\title{
REVIEW OF THE EXTINCT FAMILY SYNTONOPTERIDAE (ORDER UNCERTAIN)*
}

\author{
By Frank M. Carpenter \\ Museum of Comparative Zoology \\ Harvard University, Cambridge \\ MA 02138, USA
}

The family Syntonopteridae was named by Handlirsch in 1911 for a new genus and species, Syntonoptera schucherti, from the Upper Carboniferous of Mazon Creek, Illinois. Although the unique specimen on which the species was based consisted of only a wing fragment, the presence of several intercalary, triad veins was of unusual interest. During the $\mathbf{7 5}$ years that have passed since then, only six additional specimens of the family have been found (Carpenter, 1938, 1944; Richardson, 1956), all of them in the Mazon Creek beds. The latest of these specimens was sent to me for study by Dr. E. S. Richardson, Jr., a few months before his death, and I have only recently had the opportunity to study it and prepare illustrations. While working on this fossil, I decided to reexamine at the same time the other five specimens in the family known to me. A review of these specimens is included here, followed by revised diagnoses of the family and of the two known genera.

Genus Syntonoptera Handlirsch, 1911, p. 299.

Type species: S. schucherti Handlirsch, 1911. Type specimen, no. PM0019, Peabody Museum, Yale University.

This genus was based on a single specimen consisting of the reverse half of an incomplete fore wing (Fig. 1). As preserved, the specimen is $80 \mathrm{~mm}$ long but the complete wing was probably nearly $100 \mathrm{~mm}$ long. It lacks the proximal and distal areas of the wing, as is often the case with insects preserved in concretions. It does show clearly, however, the triad branching of MA, MP, and CUA. The distal part of RS, which presumably had a triad also, is not preserved. Handlirsch's figure $(1911$, p. 3$)$ is correct in most respects

*Research supported by National Science Foundation Grant DEB 8205398, F. M. Carpenter, Principal Investigator. 

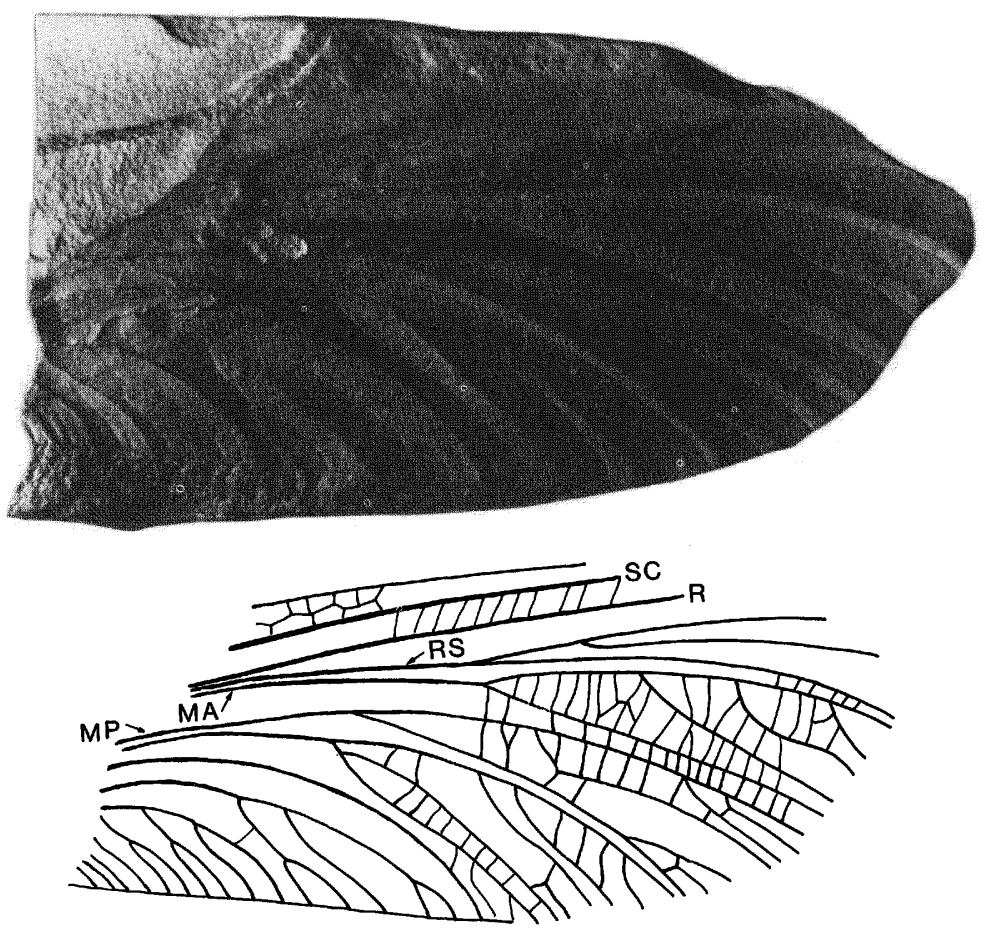

Fig. 1. Syntonoptera schucherti Handlirsch, fore wing. Upper figure: photograph of holotype, No. YPM19, Peabody Museum, Yale University. Length of wing fragment, $80 \mathrm{~mm}$. Lower figure, venational pattern of holotype.

but it does depict the stem of MA as close to the stem of MP. These two veins are, in fact, widely separated, MA being very close to RS, and MP being close to CUA, which is a generic trait of the fore wings.

A second fragment of a fore wing of Syntonoptera (presumably schucherti) was found in the Langford collection (specimen no. 14881) of the Illinois State Museum, at Springfield (Carpenter, 1944). This specimen is nearly the size of the type and includes about the same area of the wing, but it is not so well preserved. In my figure of the specimen I represented with dotted lines the probable 


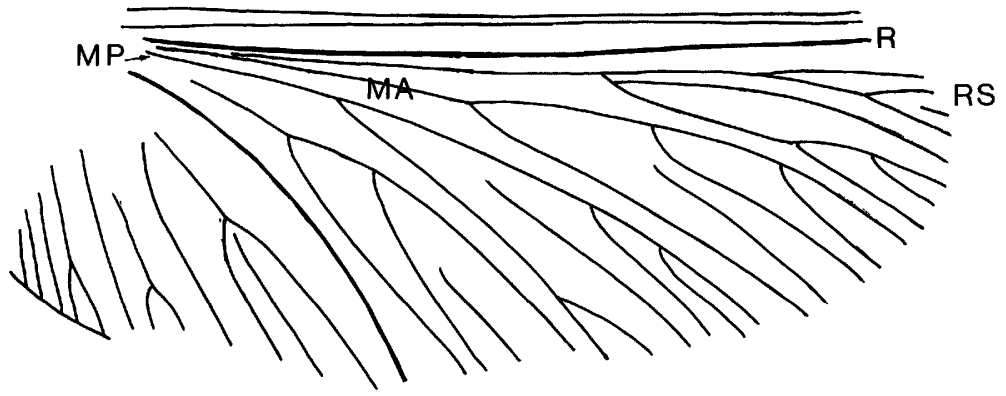

Fig. 2. Syntonoptera schucherti Handlirsch, hind wing. Venational pattern of specimen in Fig. 3b.

basal segment of MA diverging from MP to $R$, since that area was damaged in the fossil. I now think that the divergence probably occurred nearer the wing base. The wide area between MA and MP is like that of the type of schucherti.

The specimen that Dr. Richardson sent me a few years ago is in the collection of the Field Museum of Natural History, Chicago. It was found by Ida Thompson at Pit 11, Will County, Illinois, in 1928 , and has the catalogue number PE16216. It consists of a nearly complete wing, lacking some of the base and a little of the apex. (Fig. 3). It is $100 \mathrm{~mm}$ long, as preserved, and probably had an original length of $110 \mathrm{~mm}$. Since the size and venation are consistent with those of the type of schucherti, I consider this to be the hind wing of that species. Although more of the wing area is preserved than in the other two specimens, the preservation is not as good as that of the type. Only vague indications of the cross veins can be seen. The costal area, as usual in hind wings, is narrow, only about a third as wide as the subcostal area. (Fig. 2). The stem of RS is very close to the base of $R$ but its actual origin has broken away. The base of MA is also very close to RS but, in contrast to the fore wing, MP is very near MA, indicating that the basal piece of MA, diverging from M, must have been very short. CUA and CUP are essentially as in the fore wing except that CUA, a very strong vein, is more oblique and curved. The anal veins are similar to those of the fore wing but with a difference of inclination because of the broad anal area. 
[Vol. 94

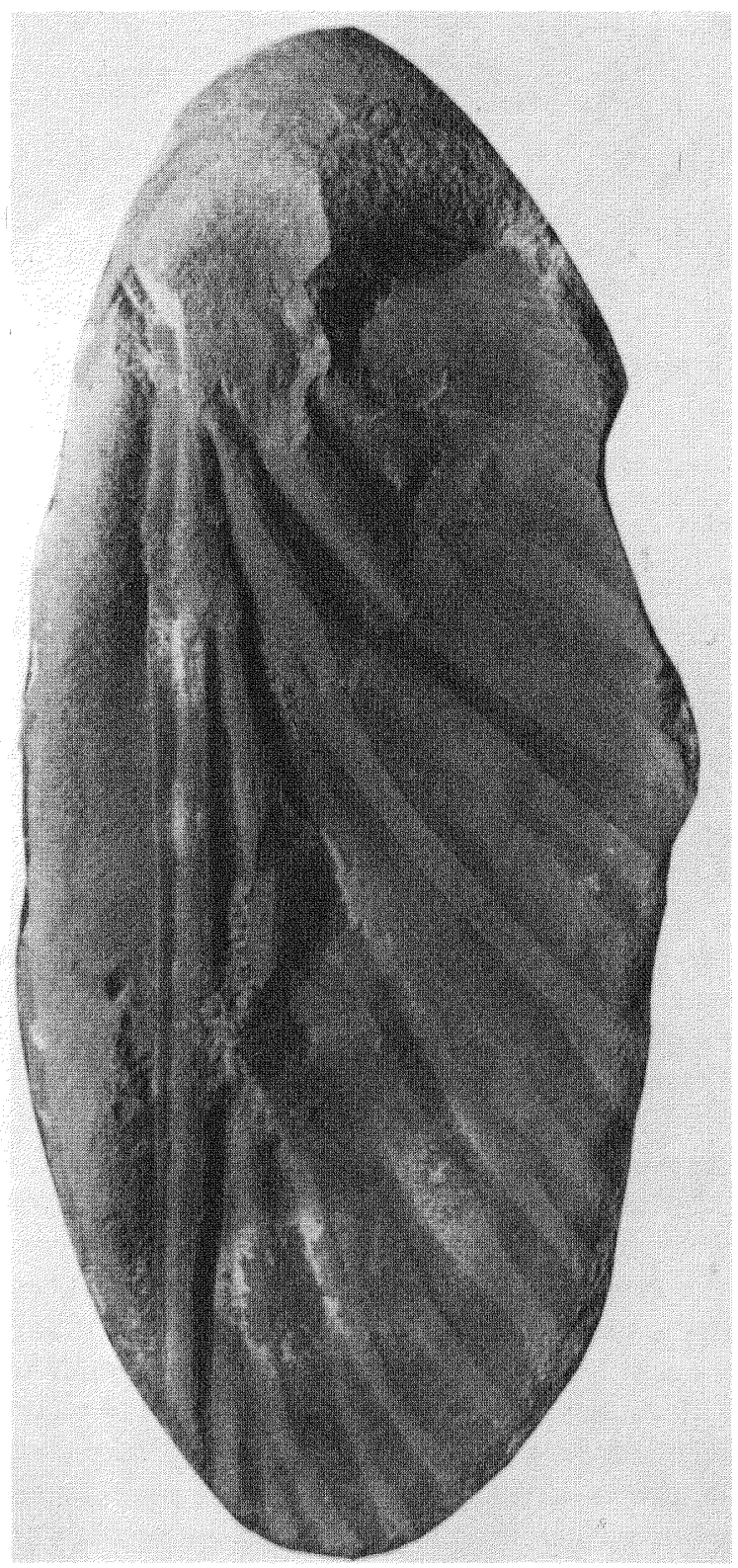

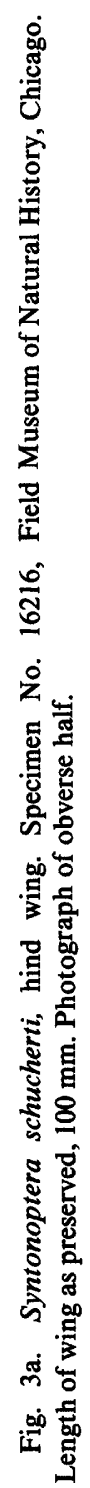




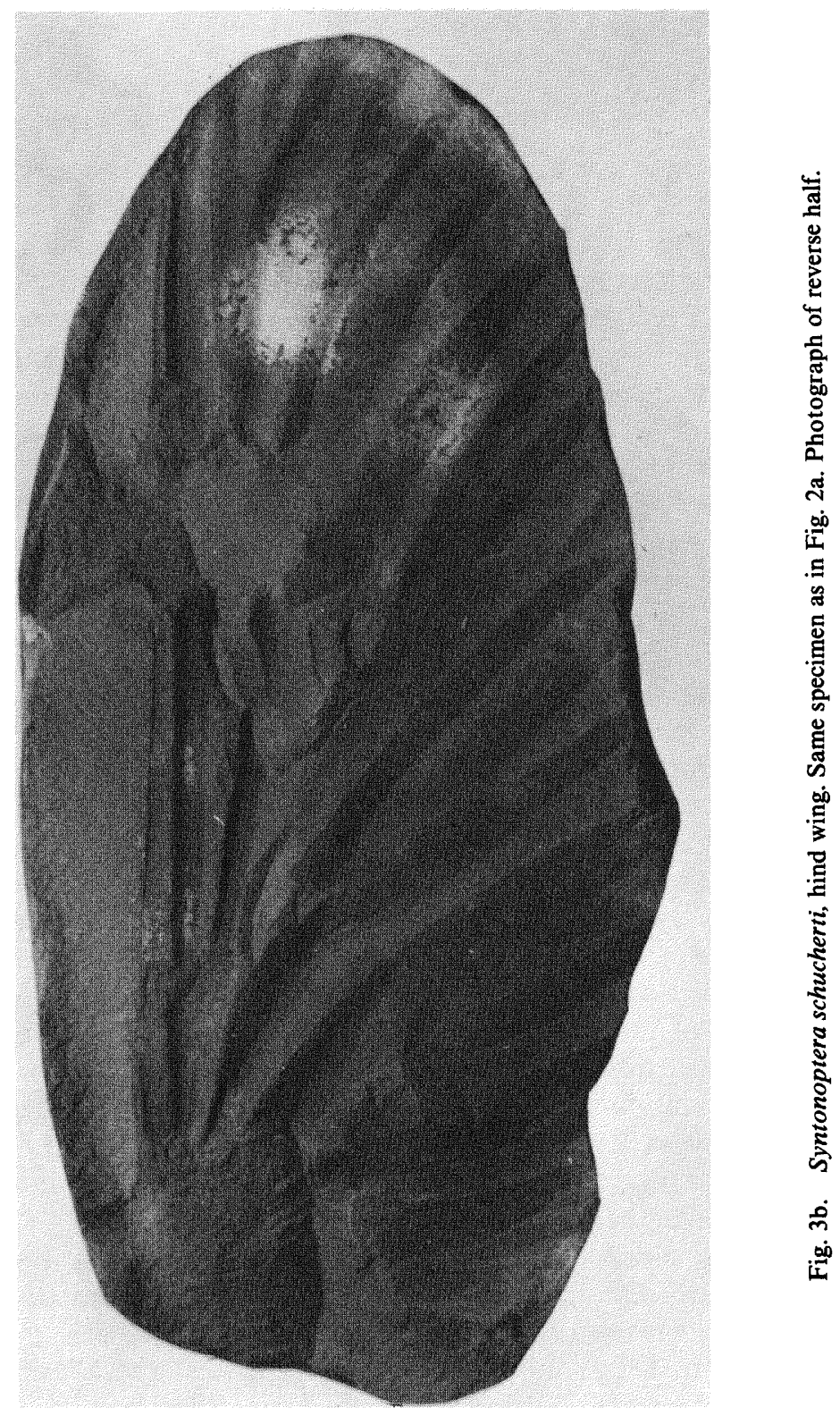


Genus Lithoneura Carpenter, 1938, p. 446.

Type species: L. lameerei Carpenter, 1938. Type specimen: no. 24537, Museum of Comparative Zoology, Harvard University.

This genus was based on a species known only by the type, consisting of a dorso-ventral view of the insect, with its four wings spread (Fig. 4). It is an interesting and important specimen, since it shows at least portions of fore and hind wings, as well as a few details of body structure. The wings are well preserved, except for the apical areas, which are not included in the concretion. The fore wing (Fig. 5, upper), which is $32 \mathrm{~mm}$ long as preserved, has a distinctly curved anterior margin, as least as far as the level of the midwing. The basal part of RS, although close to stem R, is independent of it. M is separate from RS basally but at about one-fourth the wing length from the base MA diverges anteriorly and merges with RS before diverging posteriorly as an independent vein; RS, MA, MP, and CUA have the triad, intercalary veins as in Syntonoptera. The hind wing (Fig. 5, lower) of lameere $i$ has a very distinctive shape, being unusually broad in the anal, cubital, and medial areas. As in the fore wing, RS is independent of R basally. However, the stem of $M$ is coalesced with the stem of CUA, and $M$ divides into MA and MP, shortly after its divergence from CUA. MA is coalesced with RS as in the fore wing, and RS, MA, MP, and CUA have the intercalary, triad branches.

The body structures preserved in the type of lameerei are very limited (Fig. 6). These include the general thoracic area, part of the abdomen, and what appear to be parts of the head. In my original account of this specimen (Carpenter, 1938, p. 445) I stated that prothoracic lobes were "present, though small." In the light of fifty years of additional experience with fossil insects, I am not as confident now as I was then that the prothoracic lobes are, in fact, present; a slight, local differentiation in the texture of the rock matrix might be misleading.

In this connection, I should mention that Dr. Kukalová-Peck has published an account of her observations on the structure of the type of lameerei. I find that her figure (Kukalová-Peck, 1985, fig. $11)$ is more in the nature of a reconstruction than a record of what is actually preserved. She states in her account: "The head is a composite impression of the dorsal and ventral head structures; the eyes 


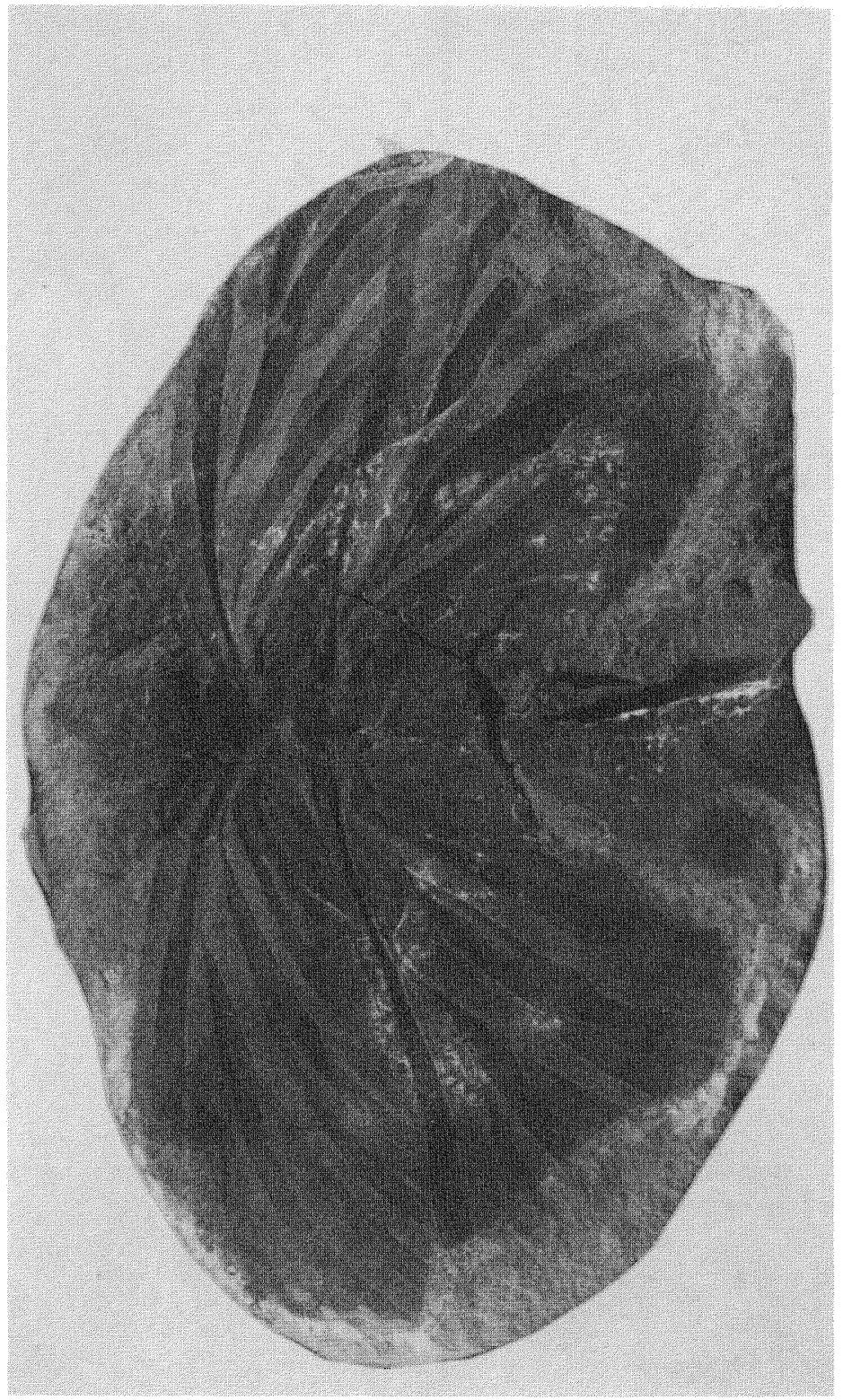

蛋

흉

胥

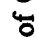

急

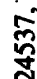

¿̇

政

흥

농

롱

䒿

홍

ذ્

음

ชึ 몸

으

ะั้ 틈

ริ ำ

帘

+ 究

证密 

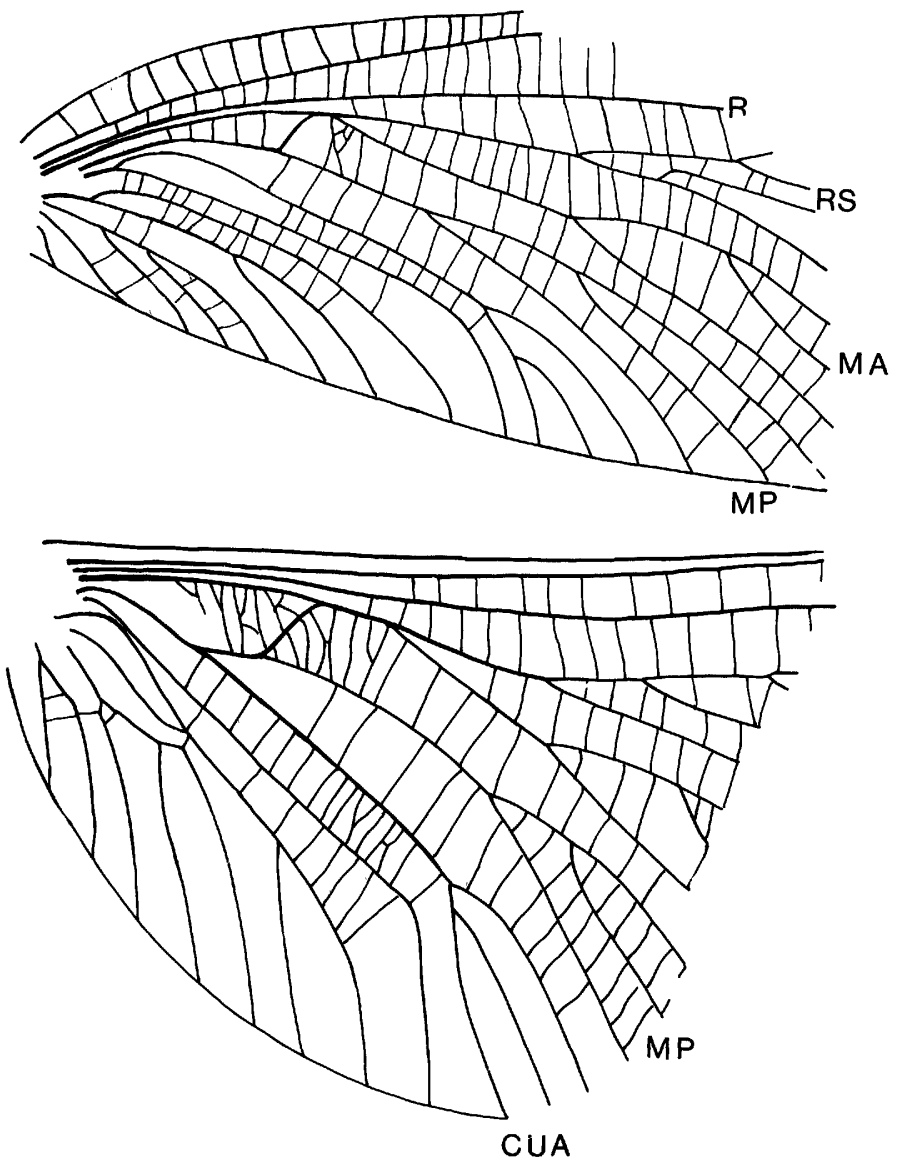

Fig. 5. Lithoneura lameerei Carpenter. Venational pattern of fore wing (upper figure) and hind wing (lower figure). 


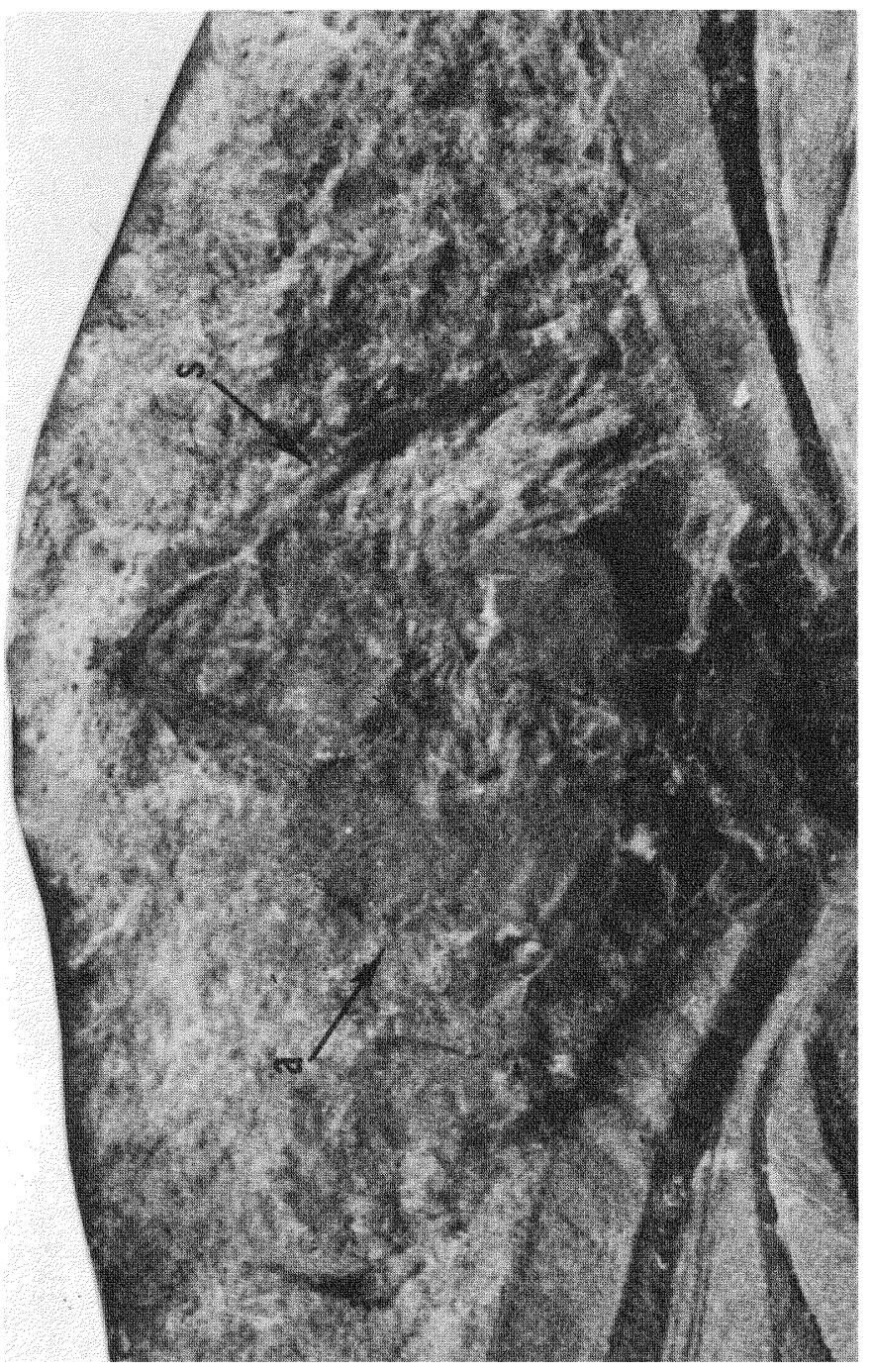

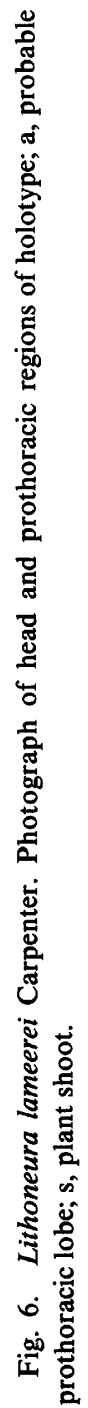


are very large and bulging; and the antennae are long, multisegmented, and relatively thick; the prothorax carried two large prothoracic wings, which were previously noted by (Carpenter 1938)." The head and thoracic area of the insect can be seen in the accompanying photographs (Figs. 4 and 6) at different magnifications. As shown in these figures, there seems to be a small prothoracic lobe (a) on the left side of the prothorax, noted in my original account of the specimen. This is only $2 \mathrm{~mm}$ wide. Anterior to it, on the same side, Kukalová-Peck has drawn a large, bulging eye. I had assumed in my account that the prothoracic lobe included that area, making the lobe about $5 \mathrm{~mm}$ long. I do not see anything on either side of the head resembling the two large eyes she has drawn. She has also included in her figure a pair of "pleisiomorphic" antennae, with numerous segments, arising from the head. I did not refer to those structures in my 1938 paper because I was convinced they were of plant origin. I recently brought the fossil to Professor Andrew H. Knoll, Curator of the Paleobotanical Collection at the Harvard University Herbaria, for his examination. He subsequently reported to me that the structures were without question the shoots of vascular plants (Fig. 6). The numerous segments, shown in KukalováPeck's figure, are not present in the fossil [See figures 4 and 6]. Also, I am unable to see any indication of the segmented piece of the antenna shown in her figure as arising from the right side of the head. There is one "joint" on a shoot near the front margin of the right wing, but this is typical of the "joints" that occur on shoots of many Carboniferous plants, especially among the Arthrophyta and other articulates. We do not yet know the nature of the antennae of Lithoneura.

In 1944 I described Lithoneura mirifica, a second species of the genus, based on a well-preserved, though wrinkled, hind wing (Fig. 7), the only complete wing so far known in the family. The holotype, no. 14880ab, is in the Langford collection of the Illinois State Museum, at Springfield. The wing is $85 \mathrm{~mm}$ long, about twice the size of lameerei. It is differently shaped from the hind wing of lameerei, being more nearly oval, and having a convex anterior margin and a broader anal area. The venation is close to that of lameerei, so far as the latter is known.

A third species of the genus, carpenteri, was named by Richardson in 1956 (Fig. 8). The holotype, no. 45248AB in the Walker 


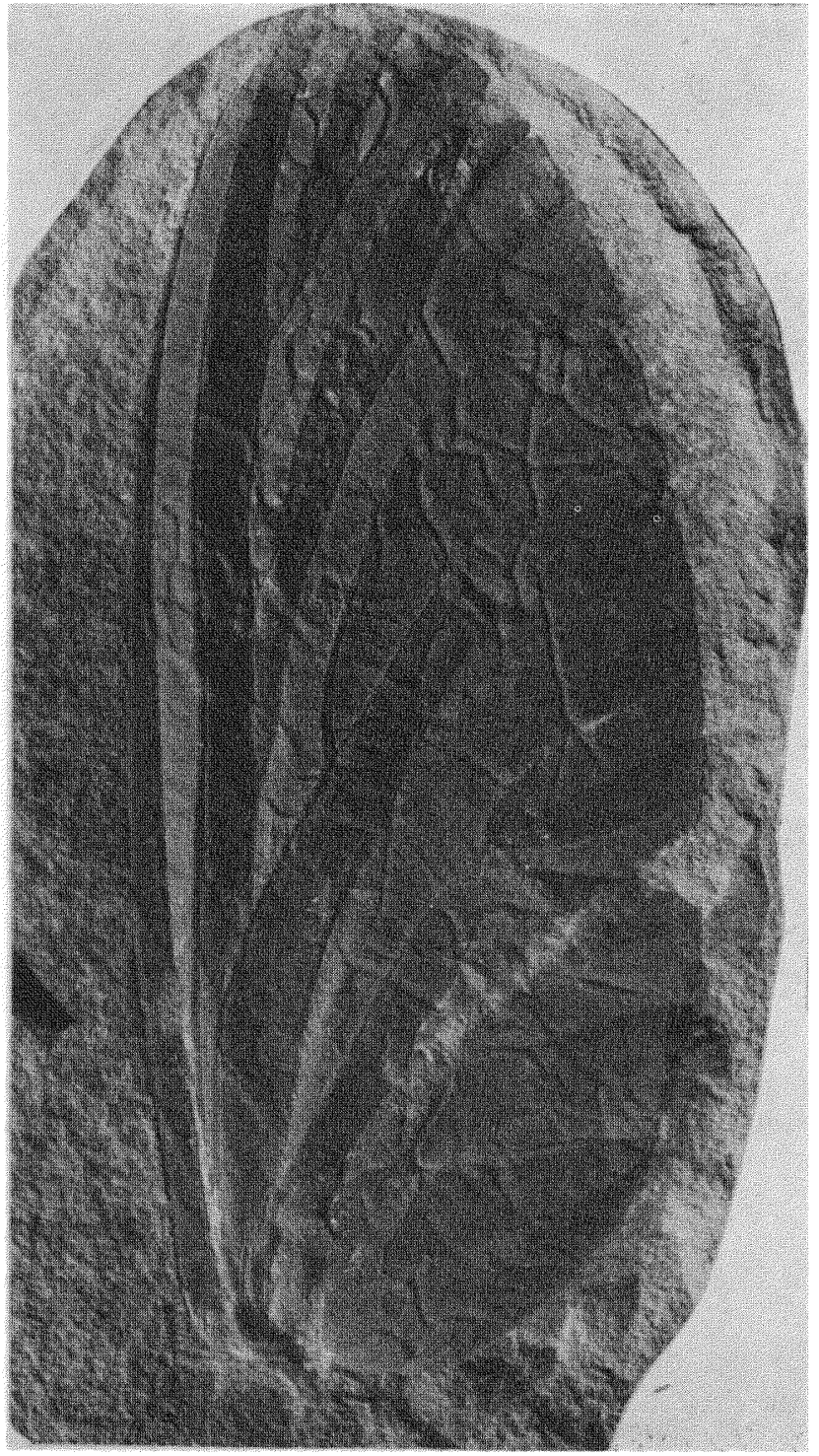

章 

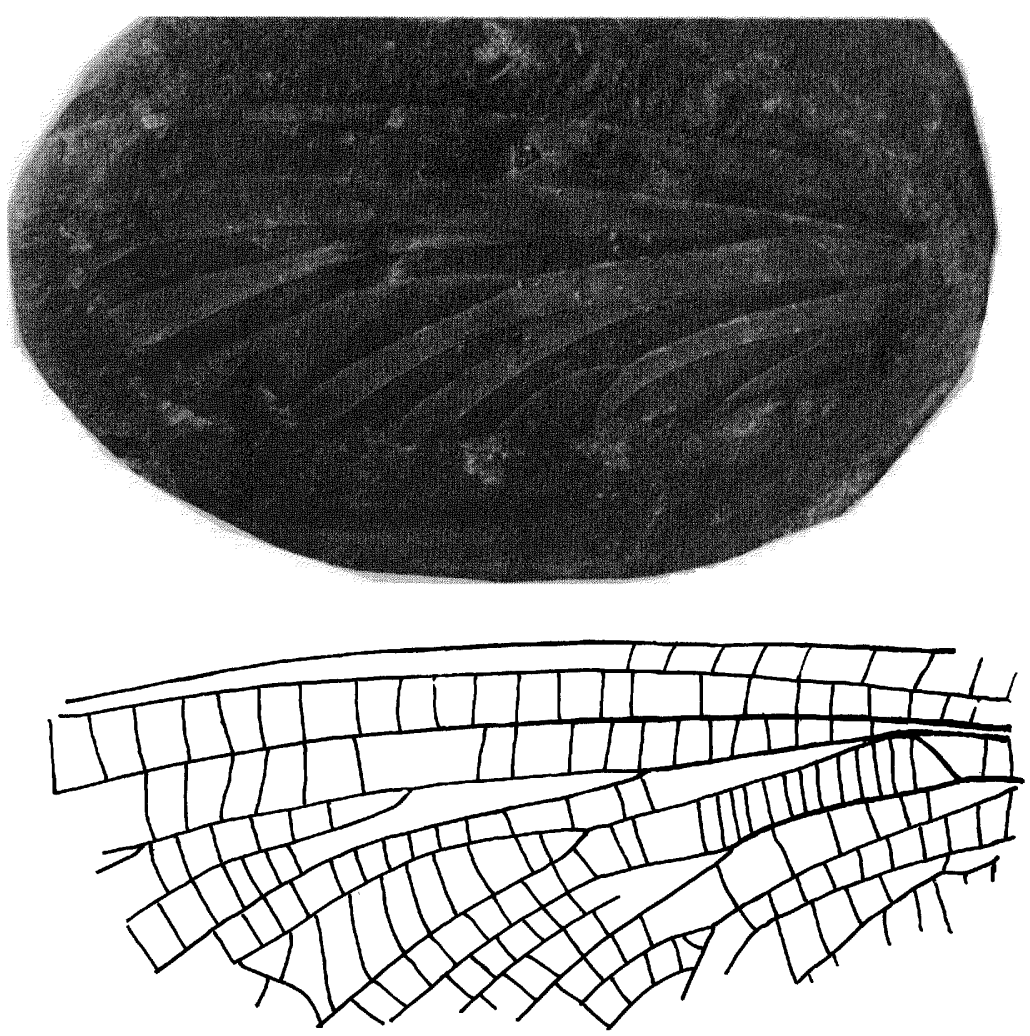

Fig. 8. Lithoneura carpenteri Richardson, fore wing. Holotype, No. 45248, Walker Museum, University of Chicago. Length of fragment, $55 \mathrm{~mm}$. Upper figure, photograph of type; lower figure, venational pattern.

Museum, University of Chicago, consists of an incomplete fore wing, about $55 \mathrm{~mm}$ long. The original wing was probably about the same size as mirifica. This is almost certainly the same as mirifica; allowing for the difference in wing shape, the venation is virtually the same in the two holotypes.

Finally, the fourth specimen, no. 299 in the collection of Mr. and Mrs. Frank Wolff, was found in 1968 and has not previously been reported. It consists of a small basal fragment of a hind wing of mirifica, about $28 \mathrm{~mm}$ long. The costal area is not preserved but the fossil does show very well the separation of R and RS basally (Fig. 9). 


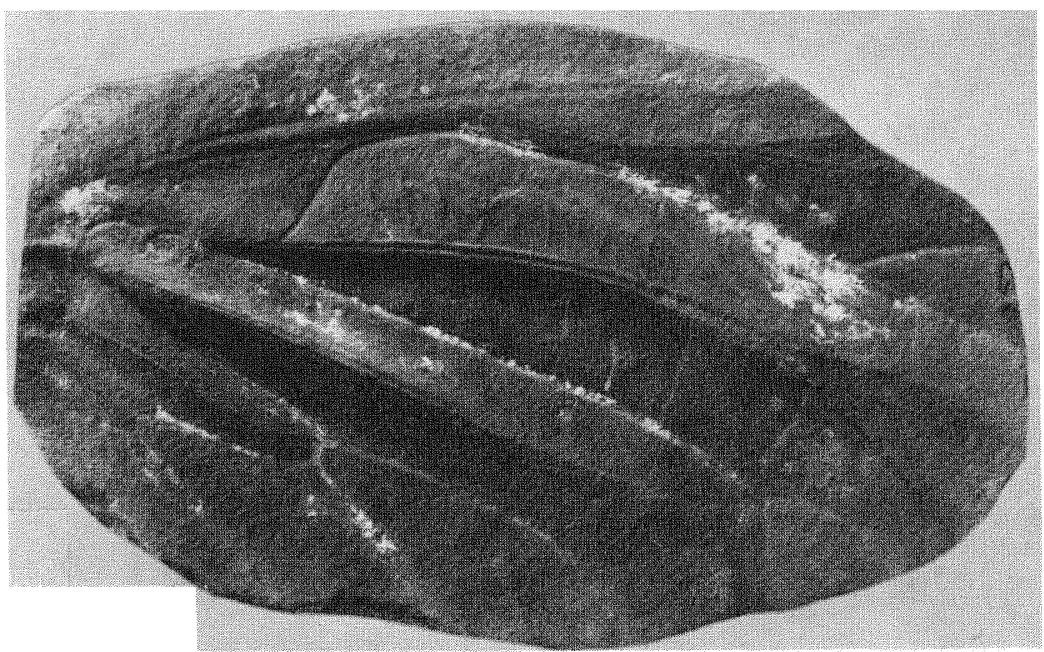

Fig. 9. Lithoneura mirifica Carpenter, hind wing. No. 299, Wolff Collection. Length of fragment, $28 \mathrm{~mm}$.

\section{Diagnosis of FAMIly Syntonopteridae}

Medium-sized to large insects. Fore wing (incompletely known): costal area relatively broad proximally, very narrow distally; $\mathbf{R}$ without branches; stem of RS independent of stem R; stem of MA either close to RS or coalesced with it for brief interval; RS, MA, $\mathrm{MP}$, and CUA with intercalary, triad branches; cross veins numerous, but rarely branched. Hind wing: broader than fore wing basally; venation essentially as in fore wing, but slightly modified by wing shape. Body: little known. Pronotum apparently with small lateral lobes. Antennae, mouthparts, legs, and cerci unknown.

\section{Genus Syntonoptera}

Fore wings: costal area with at least some reticulate cross veins; stem of MA very close to stem of RS; stem of MP remote from stem MA. Hind wing: venation as in fore wing but stem of MP very close to stem of MA.

\section{Genus Lithoneura}

Fore wing: cross veins in costal area without branches; stem of $\mathbf{M}$ remote from RS near wing base but then abruptly diverging anteriorly to RS and coalescing with it for a short interval. Hind wing: 
stem of $M$ coalesced with stem of CUA basally; anal, cubital, and medial areas very broad.

\section{Discussion}

In the article cited above (1985), Kukalová-Peck described two specimens of nymphs, Lithoneura piecko and $L$. clagesi, from the Mazon Creek deposit, placing them in the order Ephemeroptera, family Syntonopteridae. Since the nymphs have a median caudal process, as well as the cerci, I agree that they are Ephemeroptera. Both of these nymphs had, in fact, been sent to me for study by Dr. Richardson many years ago. In a preliminary manuscript on them, I placed them in the Carboniferous genus Triplosoba Brongniart, family Triplosobidae, from Commentry, France. The type species of Triplosoba, pulchella Brongniart, is known by a single specimen, an imago having the three caudal appendages as well as an ephemeropterous venation, and is the only Carboniferous insect that has been consistently placed in the order Ephemeroptera. Since the two Mazon Creek nymphs showed no significant venation, I discontinued working on them, with the hope that better preserved nymphs might be found. However, in my opinion the assignment of these nymphs to the Syntonopteridae is very questionable, since the latter family is not, with certainty, a member of the order Ephemeroptera. It is quite possible that the two nymphs belong to the family Triplosobidae. In this connection, it is worth noting that several genera of insects are found in both the Commentry shales and the Mazon Creek beds. One of these, Mischoptera, of the order Megasecoptera, is represented by several imagoes in the Commentry deposit, although no nymphs of the genus have been found there; on the other hand, several specimens of nymphs, with the same venation and body structure, have been found in the Mazon Creek concretions (Carpenter \& Richardson, 1968).

The precise affinities of the family Syntonopteridae are uncertain. Handlirsch $(1911,1919,1922)$ placed it in the order Palaeodictyoptera, but of course he knew the family only by a small wing fragment, the holotype of $S$. schucherti. In 1938 and 1944, following my study of the specimens of Lithoneura, I suggested that the family may have been intermediate between the Palaeodictyoptera and the Ephemeroptera. A few years later, Edmunds and Travers (1954), linking the Syntonopteridae with both orders, proposed that the 
Palaeodictyoptera might have been derived from the order Ephemeroptera. These ideas, however, were suggested before it was generally known that the Palaeodictyoptera had long, haustellate beaks. That had actually been shown by Laurentiaux in 1952, but there was some delay before its significance was fully appreciated. The following year, Laurentiaux (1953) designated a new order, Syntonopterodea, for the family. He did not, however, indicate any characters that would separate the new order from all others. More recently, Kukalová-Peck (1983) has placed the family Syntonopteridae in the order Ephemeroptera. In my opinion, we do not yet know enough about the body structure of the Syntonopteridae, including the mouth-parts and the terminal appendages of the abdomen, to justify that decision. As pointed out by Edmunds and Traver (1954), the Syntonopteridae may prove to have had two cerci plus a median caudal filament like the Ephemeroptera, when sufficiently well-preserved specimens are found. In that case, and provided they do not have haustellate mouthparts, their assignment to the Ephemeroptera would be justified. Until then, I prefer to place the Syntonopteridae in the category of Palaeoptera, Order Uncertain.

\section{Literature Cited}

Carpenter, F. M.

1938. Two Carboniferous insects from the vicinity of Mazon Creek, Illinois: American Journal of Science, ser. 5, 36: 445-452, text-fig. 1-3.

1944. Carboniferous insects from the vicinity of Mazon Creek. Illinois: Illinois State Museum, Scientific Papers, 3 (1): 1-20, text-fig. 1-4, pl. 1-4.

Edmunds, G. F., JR. AND Traver

1954. The flight mechanics and evolution of wings of Ephemeroptera, with notes on the archetype insect wing: Journal of the Washington Academy of Sciences, 44: 390-400.

HaNDLIRSCH, Anton

1911. New Paleozoic insects from the vicinity of Mazon Creek, Illinois: American Journal of Science, ser. 4, 31: 297-326, text-fig.

1925. Paläontologie, in Schroder (ed.), Handbuch der Entomologie, 3, 118-306, text-fig. 52-237. Fisher (Jena).

Hubbard, M. D. and J. KuKalova-Peck.

1980. Permian mayfly nymphs: new taxa and systematic characters, in Advances in Ephemeroptera biology (Flannagan and Marshall, ed.) pp. 19-31, text-fig. 1-3. 
KukalovA-Peck, J.

1985. Ephemeroid wing venation based upon new gigantic Carboniferous mayflies and basic morphology, phylogeny, and metamorphsis of pterygote insects (Insecta, Ephemerida): Canadian Journal of Zoology, 63: 933-955, text-fig. 1-39.

LAURentiauX, Daniel

1953. Classe des Insectes (Insecta, Linné, 1758), in Pivetaux (ed.) Traité de Paleontologie, 3: 397-527, text-fig. 1-106, pl. 1.

1952. Presence d'un rostre eugeronien chez le paléodictyoptëre Stenodictya lobata Brongniart. Affinites des protohemiptëres: Comptes Rendus Hebdomadaires des Seances de l'Academie des Sciences, 234: 1997-1999.

Richardson, E. S., JR.

1956. Pennsylvanian invertebrates of the Mazon Creek area, Illinois: Fieldiana Geology, 12(4): 3-76, text-fig. 1-41. 

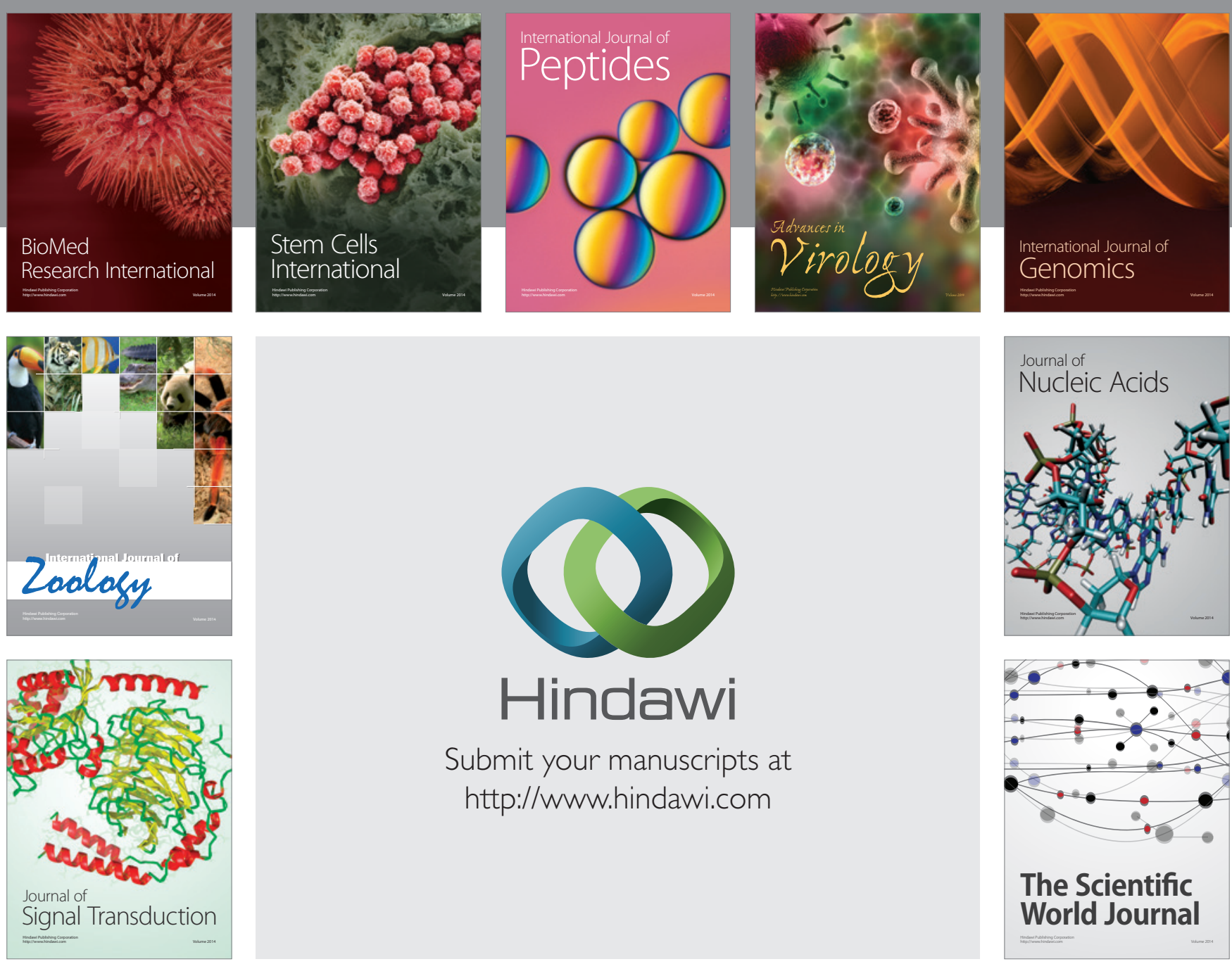

Submit your manuscripts at

http://www.hindawi.com
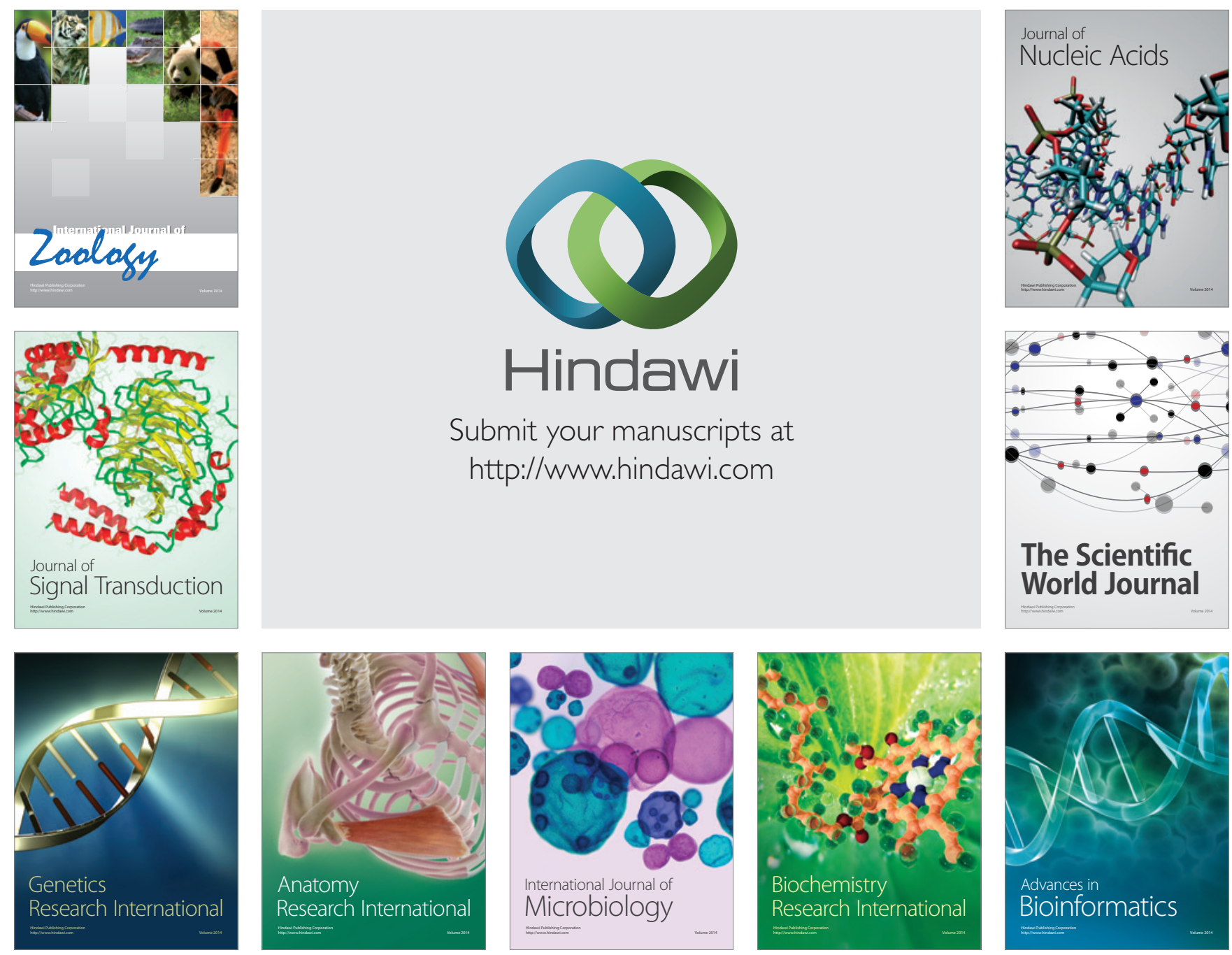

The Scientific World Journal
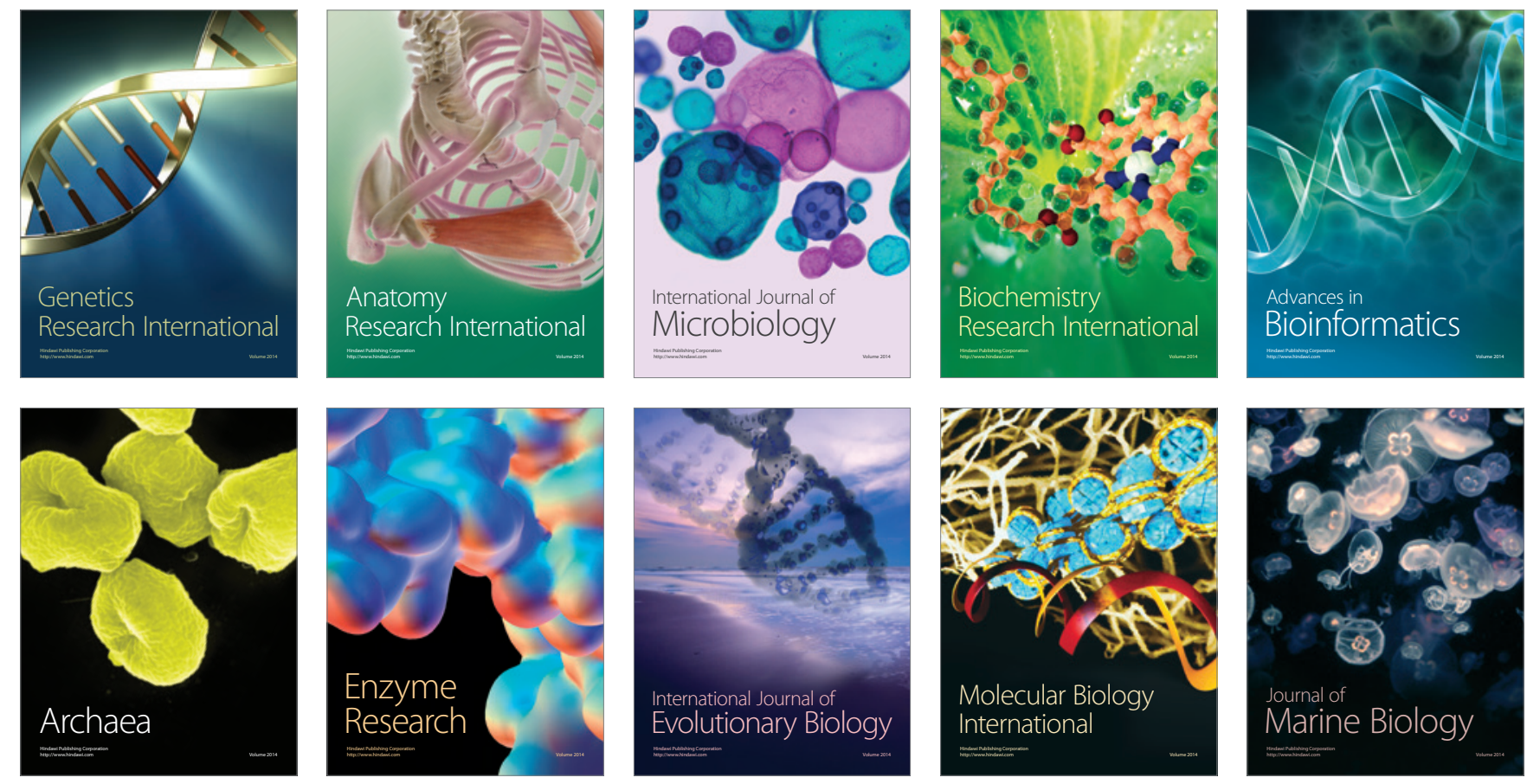